\title{
FÉLICIEN DAVID E “A PÉROLA DO BRASIL”.
}

Há pouco mais de um século, em 22 de novembro de 1851, na Ópera Nacional de París, foi representada pela primeira vez La Perle du Brésil, ópera em três atos, baseada na peça de J. Gabriel e Sylvain Saint-Etienne e música de Félicien David.

O título da ópera e o nome de seu compositor pouco significam para nós hoje em dia. A ópera perde-se entre as muitas centenas de óperas lembradas hoje apenas por um ou outro trecho ou, então, apenas pelo título. O compositor mal aparece nas nossas histórias da música e. se não fôsse uma ária de sua ópera "brasileira", interpretada por algumas das maiores coloraturas de nossos dias, seu nome nem apareceria nos registros discográficos. No entanto, Félicien David teve um lugar de destaque no romantismo musical francês e sua ópera pode ser citada como exemplo de uma certa corrente ou tendência (talvez melhor mentalidade) resultante e, até certo ponto característica dêsse mesmo romantismo. E' o que procuraremos recordar nestas breves notas.

Nascido aos 13 de maio de 1810, em Cadenet (Vaucluse) e falecido em París aos 29 de abril de 1876, Félicien David fêz em sua cidade natal e com o próprio pai os primeiros estudos de música. Ingressou no Conservatório de París, estudando com Fétis, Benoist e Lesueur. Por influência de um amigo, o pintor Paul Justus,-interessou-se pela doutrina de Saint-Simon, exposando as idéias do mestre com um fervor verdadeiramente apostólico, que o levou a pretender consagrar a própria arte à nova crença, vindo a ser como que um Palestrina ou um Santo Ambrósio do sansimonismo (1). Viajou pelo Oriente com o objetivo de propagar os ensinamentos, os únicos ensinamentos, segundo acreditava, capazes de salvar a humanidade, através de um mixto de religião e de ciência, a que se juntavam muito misticismo e muita tolice. Entretanto, sua capacidade musica! foi inferior ao seu fervor apostólico e a contribuição artística que pôde dar à sua fé limitou-se a algumas peças medíocres, entre as quais um côro sur la prison du Père Enfantine, escrito por ocasião do fechamento do tempo sansimonista de Menilmontant. Todavia pretendeu escrever até uma sinfonia sôbre a divisa de Saint-Simon $A$ chacun suivant sa capacité, à chaque capacité suivant ses oeurves

(1). - "Il luit appartenait d'être le Saint Ambroise du nouveau culte en créant, en remplissant tout au moins les formes liturgiques convénant à ses cérémonies" (René Brancour, Félicien David). 
- "thème peu susceptible ( $\mathrm{diz}$ Brancour) de dévelopments musicaux et qui heureusement demeura stérile."

Este contacto com as terras orientais marca o primeiro traço característico de sua obra. De fato, voltou a París em 1835, "avec une rêve d'Asie incomplète, mais de impressions suffisantes pour que désormais sa sensibilité et son imagination fussent conquises par l'exotisme" (Combarieu). Brises d'Orient, Mélodies Orientales e, principalmente Le Désert são os pontos mais altos desta sua tendência exótica. Esta última peça, sôbre texto de Auguste Colin (outro sansimoniano) pareceu revelar aos contemporâneos uma nova fôrça musical. Trata-se d'uma obra descritiva, através da qual todos os aspectos do deserto são evocados: a caravana, a noite, a fantasia, as danças, o canto do muezzin, etc. O êxito de Le Désert foi imenso, levando um dos críticos parisienses, Castil Blazé, a considerar a música "real, viva, emocionante, sedutora, superior a de quantas óperas são hoje representadas nos nossos teatros" (2). Entusiasmado, tentou outros trabalhos nesse gênero, com resultados muito desiguais - Moise au Sinai, Cristoph Colomb, L'Eden.

$\mathrm{O}$ exotismo de Félicien David marcou época e teve, pelo menos, o mérito de substituir por algo de mais inspiração ou de mais real, a turquerie de fins do século XVIII e princípios do século XIX. Esta mania do orientalismo invadiu a música européia nos últimos anos dos mil e setecentos. Três óperas de grande interêsse e que alcançaram real consagração em seus dias podem ser tomadas como ponto de partida dessa curiosidade musical: $O$ tapto do serralho, de Mozart (1782), O califa de Bagdá, de Boildieu (1800) e Abu Hassam, de Weber (1810). Convem insistir na palavra que empregamos: curiosidade. Por muito tempo a chamada influência oriental será apenas isso. De então para cá, a mania alastrou-se por tôda a parte. Se, por um lado, produziu trabalhos de valor no domínio da música dramática ou sinfônica, como as óperas de Bizet (Pessadores de pérolas), - de Delibes (Lakmé), de Cornelius (O Barteiro de Bagdá), ou como o esbôço sinfônico em que Borodine descreve as estepes da Ásia central, ou ainda como a delicada página de Rimsky-Korsakov inspirada num dos contos das mil e uma noites, por outro lado descambou para a maior banalidade que se possa imaginar, inundando a Europa com uma verdadeira enxurrada de música de salão inspirada num pseudo-orientalismo vasio e inexpressivo, com os mais variados sabores, árabe, chinês ou japonês, conforme o gôsto do público a que se destinasse a música. . Mssmo a música lírica sofreu essa pernicicsa influência, dela não se livrando nem um compositor do mérito de Puccini que, apenas em Turandot tentou uma reabilitação da banalidade de Madame Butterfly. Mas, como nem sempre tentar significa conseguir, seu esfôrço pouco adian-

(2). - Cit. por René Dumesnil, La musique romantique française, 201. 
tou para a maior valorização de sua música, embora naquela ópera empregasse algumas legítimas melodias chinesas.

A culpa aqui talvez caiba menos à musica do que à literatura. Compositores do período romântico não fizeram muitas vêzes senão acompanhar a tendência de romancistas e novelistas que encontravam em temas orientais inexgotável fonte de inspiração para suas obras. Assim, o exotismo musical não é senão conseqüência do exotismo literário, tão do agrado do espírito francês dos meiados do século XIX.

Após êsse exotismo oriental, foi a música européia empolgada por outra espécie de exotismo, desta vez tomando por temas assuntos ligados aos países colonizados pelos europeus: India, África, América. . E ainda desta vez, também apoiada pela literatura. Assim como aquela dignificação do bom selvagem, inspirada nas obras dos cronistas e viajantes dos séculos XVI, exerceu considerável influência sôbre as correntes do pensamento europeu no século XVIII, desta vez é à literatura que cabe aproveitar êsse inesgotável filão. Os temas versados referem-se sempre aos primeiros anos da colonização, motivo pelo qual Carlos Gomes, em 1870, vai sentir-se bem à vontade para encher o palco do Scala de Milão de indígenas brasileiros, pois em outras óperas já haviam aparecido, antes, nativos da India, da Austrália, do norte da África. A tendência à dignifi:ação dos nativos que encontramos em David, em Meyerbeer, em Bizet e em Gomes é apenas uma das muitas tendencias da ópera do século XIX. Como houve, em certa época, uma tendência à dignificação dos defeitos físicos (Rigoleto, $A$ muda de Portici) e das transviadas (Manon, Bohème, Traviata), à exaltação do preconceito racial (La Juive), do preconceito religioso (Huguenotes, $\boldsymbol{A}$. profeta), do ciúme (Otelo), da infidelidade conjugal (Ballo in maschera, Cavalleria rusticana, Os palhaços), dos heróis pouco conhecidos (Rienzi, Simão Bocanegra, As vésperas sicilianas), das assuntos bíblicos (Sansão e Dalila, Moisés), das lendas medievais (Tristão e Isolda, Parsifal), das lendas germânicas (a tetralogia wagneriana), do triunfo do espírito sôbre a matéria (Fausto, Tannhauser) e por ai afora...

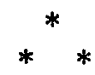

No meio de tôdas essas preocupações, sensatas ou tolas, que encontramos na música romântica francesa, Félicien David pretendeu realizar algo de sólido e não se pode negar que exerceu alguma influência sôbre as novas gerações de compositores; provàvelmente a ela se deverá atribuir a existência de algumas obras musicais, que ainda hoje são ouvidas, e com maior frequêencia que as do próprio David. Citemos, entre outras, é só em França, as de Reyer (La Statue), Bizet (Djamileh, Les Pêcheurs de perles), Gounod (La reine 
de Saba), Delibes (Lakmé), Massenet (Le roi de Lahore), Saint Saens (Nuit persanne, Suite algérienne).

Dentro daquela outra tendência à dignificação das virtudes dos indígenas enquadra-se $A$ Pérola do Brasil, o primeiro trabalho de grandes proporções que Félicien David escreveu para a cena. Sua première realizou-se, como já foi assinalado, em 22 de novembro de 1851, na Opera Nacional de París. Foi representada novamente em 1857 no Teatro Lírico e, depois de revista, foi novamente encenada em 1875. Possivelmente tenha ficado nessas representações, não transpondo as fronteiras da França. Não temos notícia de ter sido levada à cena no continente americano. Divide-se em três atos, o primeiro passando-se em Lisboa, o segundo a bordo dum navio e o terceiro numa floresta do Brasil. São personagens: Don Salvador, almirante português; Lorens (sic) loco-tenente dos guardas do palácio; Rio, um marinheiro; Conde de Cavallos ( tuguês; sua esposa, a Condessa de Cavallos; Zora, jovem índia brasileira (a "pérola do Brasil"), sua serva Naouna e alguns chefes indígenas brasileiros. A comparsaria é imensa: nobres da côrte, marinheiros, soldados, indígenas. Não podiam faltar certas cenas típicas de óperas dessa natureza: baile no palácio real, festa de marinheiros, tempestade em alto mar, naufrágio, salvamento na praia, bailados indígenas e as costumeiras cenas de floresta com os cantos de pássaros, uivos de animais ferozes, espreita de inimigos, ataques iminentes de adversários, etc.

Um breve apanhado do enredo da ópera nos mostrará coisas realmente curiosas. $O$ primeiro ato passa-se num rico palácio de Lisboa, onde o Conde e a Condessa de Cavallos oferecem brilhante recepção para celebrar, entre outras cousas, o batismo de Zora, indígena brasileira, "fleur fraiche et vermeille", que havia sido levada para a Europa. Como em todos os dramas dêste tipo, Zora não é uma indígena qualquer, porém filha de importante chefe de tribo, como ela própria o diz em certa altura (". . . autrefois j'étais reine, fille d'un chef fier et puissant") e como a própria ação da ópera no último ato nos vai mostrar.

A cena inicial do primeiro ato é tôda dedicada ao batismo de Zora, o qual, entretanto, não é apresentado no palco, visto passar-se na capela do palácio. Sabemos do acontecimento pelas referências dos cantores e pelo movimento festivo em direção à capela. Rio, jovem marinheiro, põe-nos a par da situação:

\footnotetext{
"C'est notre riante merveille,

C'est Zcra, fleur fraîche et vermeille,

Que l'on va bénir en ce jour.

Pour elle quel bonheur suprême!

Elle recevra le baptême

Devant le roi, devant la cour!
}

enquanto que vozes femininas, no interior da capela, relatam o acontecimento: 
"Dieu puissant, Dieu ncíre père,

Toi qui régnes dans les cieux,

En ce jour doux et prospère,

Viens bénir nos tendres voeux!

Quand, le coeur plein d'espérance,

Nous te prisons, à genoux,

Sur cette ange d'innocence

Verse tes biens plus doux!"

A seguir, o remate da cerimônia:

"La fête est terminé,

Quelle belle journée

Pour la jeune Zora!

Longtemps encore, je pense,

On aura souvenance

De ce baptême là!

Entra Don Salvador, "brave amiral, l'honneur de tout Portugal", para anunciar aos seus marinheiros que no dia seguinte deverão partir novamente, retomando o curso de grandes viagens, apenas fortuitamente interrompidas. Homens do mar, acostumados à fúria dos elementos, deixam transparecer a alegria que a nova lhes traz: "Que importa ao bravo marinheiro que o tempo esteja sombrio ou sereno? Soberano dos mares, êle zomba das ondas furiosas. A quem vai em busca da glória, quanto maior o perigo, maior será a vitoria".

E' Rio quem nos relata, ainda, a história de Zora, levada do Brasil após a morte de seu pai numa luta sangrenta, adotada pelo almirante e que conquistou ràpidamente os favores da rainha e as atenções da côrte. No palácio da Condessa, o almirante vinha vê-la diàriamente. Isto é relatado a Lorens, loco-tenente dos guardas do palácio, por sua vez apaixonado também pela jovem indígena, e contando com o auxílio do marinheiro para uma eventual aventura .No grande baile. Zora constitui a atração de todos, muito especialmente de Don Salvador que, numa ária, talvez a mais importante dêste primeiro ato, relata-nos como, de simples protetor de Zora, veio a apaixonar-se por ela:

"Jusqu'à ce jciur sans désir, sans envie,

Je fus pour elle un guide, un protecteur;

Pour moi c'était une fille chérie,

Dont je devais assurer le bonheur.

Mais tant d'attraits, tant de grâce charmante

Dans tout mes sens ont éveillé l'amour,

Et maintenant c'est une amante

A qui je veux pouvoir m'unir un jour.

Aimable enfant, elle ignore

Dans sa naive candeur,

Cet amour qui me dévore

Et dont s'enivre mon coeur!"

Este, o ponto central do drama: Zora não só ignora que o protetor a ama, como corresponde à côrte que the é feita pelo loco-te- 
nente Lorenz, como o demonstra a sua atitude durante a festa, principalmente quando Don Salvador lhe anuncia que deverá partir com êle na viagem do dia seguinte, pois estará mais segura a bordo do que no seu palácio de Lisboa. Diante desta notícia, Lorenz, não tem outra cousa a fazer senão partir também na expedição. Não o podendo fazer livremente, conta com as boas graças de Rio, que the empresta trajes e equipagens de marinheiro e, assim disfarçado, consegue burlar a vigilância do almirante e alojar-se a bordo da nau S. Rafael.

O segundo ato transcorre em pleno mar,. a bordo da S. Rafael. O navio está todo ornamentado para uma festa em honra do almirante. Lorenz (disfarçado sob o nome de Valentim) desperta suspeitas em Don Salvador que, a propósito, interpela Rio. Este, esperto como todo marinheiro, esquiva-se às perguntas de seu comandante, o qual trata, então, de descobrir as coisas por si mesmo. Durante a festa, vale-se de hábil estratagema: anuncia o seu próximo casamento com Zora, o que deixa os amantes em situação bastante delicada, em que se traem fàcilmente. $O$ almirante interpela-o e, por uma dessas cousas que só acontece em ópera, vem a saber que Lorenz não é senão o filho dum nobre italiano, a quem, há muitos anos, numa aventura pela Itália, assassinara estùpidamente, constituindo isto motivo de constante remorso para o bravo lobo do mar. Esta revelação inesperada acalma a sêde de vingança de Don Salvador e muda, de certa forma, o curso dos acontecimentos. Diante da dificuldade de uma saída para esta situação bastante embaraçosa, os autores do drama foram bastante hábeis para inventar uma tempestade, que desviou a atenção de todos, especialmente de Don Salvador:

\footnotetext{
"Au moment où gronde l'orage,

Je me dois su salut de tout mon équipage;

Pour garder les arrêts, allez, retirez-vous!"
}

O último ato passa-se numa floresta do Brasil. A tempestade fêz o navio naufragar, atirando-o de encontro ao litoral brasileiro. Zora, ao despertar, ouvindo o chilrear dos pássaros, reconhece, pela natureza do local, encontrar-se em sua própria terra. A ária que canta - Charmant oiseau - tem sido sempre número favorito de tôdas as grandes sopranos coloraturas e realmente é das cousas mais belas que, no gênero, se conhece. Este ato é típico de uma certa espécie de ópera ou de drama que tem que terminar bem, ainda que para tanto sejam necessárias as mais absurdas coincidências: é Lorenz quem, na tempestade, salva a vida de Don Salvador; é Lorenz quem os previne do ataque dos indígenas; a tribo que ataca os portuguêses é a mesma a que pertence Zora e ela salva a situação, apresentando aos nativos o almirante como o seu generoso salvador e protetor. O chefe indígena mostra-se reconhecido: 
"En adop'ant l'enfant dont nous pleurions l'absence,

Que nous appelions tous la Pirrle du Brésil,

Tu nous as désarmés par la reconnaissance;

Ah! ne redoute plus chez nous aucun péril!"

O final não podia ser outro:

"De rétour à Lisbonne, ô ma chère Zora,

Tu recevras l'époun que ton coeur choisira!"

Entregam-se os amantes aos mais doces devaneios, enquanto o conjunto canta:

"O jour plein d'espérance,

Zo:a, par sa présence;

Sait calmer la vengéance,

Et charmer tous nos sens!

C'est notre providence,

Et telle est sa puissance,

Qu'on doit obéissance

A ses divins accents!"

E êste o enredo da ópera. Não resta dúvida que a mediocridade do drama poderia ser compensada pela excelência da música. Algumas das grandes óperas do repertório lírico mundial foram construidas sôbre os libretos mais tolos. Todavia, não foi êste o caso da Pérola do Brasil. Música e drama se equivalem, numa "dupla vulgaridade", para usar a expressão de René Brancour.

O leitor terá notado, pelo simples resumo que citamos, algumas impropriedades a atestar o pouco conhecimento que tinham os autores do drama e da música de cousas relativas a Portugal e ao Brasil. A leitura atenta do drama reforçará essa observação. Aliás, sob êste aspecto, 'A Pérola do Brasil não está isolada. As impropriedades, anacronismos e extravagâncias em que incorre, são mais ou menos comuns a tôdas às óperas européias (e até brasileiras) que pretendem retratar qualquer aspecto dos países colonizados pelos europeus. Lembremos o caso de $O$ escravo, de Carlos Gomes, cujo primeiro ato transcorre numa fazenda de café em 1567, portanto, mais de duzentos anos antes da introdução do café no Brasil... A ignorância dos libretistas sôbre as coisas da América era realmente pasmosa. E um dos pontos em que essa ignorância mais se manifesta é na confusão entre o que é português e espanhol. Assim, no caso da ópera de Félicien David, os nomes dos personagens têm sabor espanhol - Lorenzo, Cavallos, Rio, os marinheiros Diego e Muñez; no grande baile do palácio dança-se o bolero, ao som de castanholas e a bordo da $S$. Rafael dança-se a rodeña e a valsa (em $1530 \ldots$...).

Seja dito de passagem que o papel de Félicien David no romantismo francês já foi devidamente apreciado pelos historiadores 
da música francesa (3). Como sempre, os campos estão divididos, não havendo unanimidade de julgamento. Combarieu, em seu livro clássico, após analisar-lhe a obra, assim conclui: "Comme compositeur, David a des lacunes; il est inégal; il semble s'etre arrêté, sans avoir donné sa mesure, au début d'une évolution qui pouvait être magnifique et aboutir à un romantisme moins agressif que celui de Berlioz (4). René Dumesnil coloca-o ao lado de Berlioz e lamenta o esquecimento em que sua obra jaz nos nossos dias (5). GaudefroyDemombynes reconhece-lhe a importância histórica, embora reduzindo às justas proporções a comparação com Berlioz (6). Esta preocupação de compará-lo com Berlioz tentou também a J. Bruyr: "Talento sem gênio", diz êle de F. David, enquanto que o autor da Sinfonia Fantástica seria apenas um "gênio sem talento"... (7). Os seus contemporâneoś foram menos rigorosos em julgá-lo, como o atestam alguns depoimentos, principalmente o de Saint-Saens, citados nas obras de Brancour e de Combarieu (8).

Voltando à Pérola do Brasil: esta obra vale hoje pois, não só como simples curiosidade, mas também por refletir, conforme procuramos mostrar, uma certa linha de idéias, a mesma da qual sairam, entre outras óperas, Os Pescadores de pérolas, de Bizet, a Lakmé, de Delibes e $A$ Africana, de Meyerbeer, tôdas estas incomparàvelmente superiores ao trabalho de Félicien David.

\section{ODILON NOGUEIRA DE MATOS}

(3). - Afora as informaçöos mais ou menos extensas existentes nas obsas gerais de história da música, apenas um livro se encontra publicado sôbre Félizien David, o de René Brancour (ed. da Librairie Renouard) e êste mesmo de pouca valia para - conhecimento da obra do compositor. René Dumesnil, Combarieu e Demombynes dedicaram-lhe várias páginas em seus livros, conforme citações em outro loral, 0 clássico Dicionário de Grove dedica-lhe pouco mais de uma página, mas com a ponderação e segurança que o caranterizam.

(4). - Cf. Histoire de la musique, III, 116

(5). - Cf. Op. cit., 198-203.

(6). - Cf. Histoire de la musique française, 213-218.

(7). - Cf. La belle histoire de la musique, 293.

(8). - Valc a pena transcrever o depoimento de Saint-Saens: "Sa manière est singulière et déconcerte la critique par ses irrégularités. Avait-il réellement, comme on l'a prétendu, fait des études incomplètes? On le ditait, à certaines défaillances qui laissent croire par moments qu'on a sous les yeux de la musique d'amateur; mais comment expliquer alors cette finesse de touche qu'il a montrée tant de fois, cette délicatesse de coloris, cette élégance de plume qui se révèle tout à coup, et ce charme profond qui ne se trouve que dans les ma'tres? Ce n'est pas ainsi qu'écrivent les ignorants; on croirait plutôt à des accès de fablesse physique, à des intermittences maledives". Apud Csmbarieu, op. cit., 116 